\title{
Elevation alters ecosystem properties across temperate treelines globally
}

Jordan R. Mayor $^{1}$, Nathan J. Sanders ${ }^{2,3} \dagger$, Aimée T. Classen ${ }^{2,3} \dagger$, Richard D. Bardgett ${ }^{4}$, Jean-Christophe Clément ${ }^{5,6}$, Alex Fajardo ${ }^{7}$, Sandra Lavorel ${ }^{5}$, Maja K. Sundqvist ${ }^{2,8}$, Michael Bahn ${ }^{9}$, Chelsea Chisholm ${ }^{2}$, Ellen Cieraad ${ }^{10,11}$, Ze'ev Gedalof $^{12}$, Karl Grigulis ${ }^{5}$, Gaku Kudo ${ }^{13}$, Daniel Oberski ${ }^{14} \&$ David A. Wardle ${ }^{1}$

${ }^{1}$ Department of Forest Ecology and Management, Swedish University of Agricultural Sciences, Umeå, 90187 , Sweden

${ }^{2}$ Center for Macroecology, Evolution and Climate, The Natural History Museum of Denmark, University of Copenhagen, DK-2100, Copenhagen $\varnothing$, Denmark.

${ }^{3}$ The Rocky Mountain Biological Laboratory, PO Box 519, Crested Butte, Colorado 81224, USA.

${ }^{4}$ School of Earth and Environmental Sciences, The University of Manchester, Oxford Road, Manchester M13 9PT, UK.

${ }^{5}$ Laboratoire d'Ecologie Alpine, CNRS UMR 5553, Université Grenoble Alpes, CS 40700, FR-38058 Grenoble Cedex 9, France.

${ }^{6}$ CARRTEL, UMR 0042 Université Savoie Mont-Blanc - INRA, FR-73376 Le Bourget-du-Lac, France.

${ }^{7}$ Centro de Investigación en Ecosistemas de la Patagonia (CIEP) R10C1003, Universidad Austral de Chile, Camino Baguales s/n, Coyhaique 5951601, Chile.

${ }^{8}$ Umeå University, Department of Ecology and Environmental Sciences, Umeå, 90187, Sweden.

${ }^{9}$ Institute of Ecology, University of Innsbruck, 6020 Innsbruck, Austria.

${ }^{10}$ Landcare Research, PO Box 69040, Lincoln 7640, New Zealand.

${ }^{11}$ Institute of Environmental Sciences, Leiden University, Einsteinweg 2, 2333 CC, Leiden, The Netherlands.

${ }^{12}$ Department of Geography, University of Guelph, Guelph, Ontario, N1G 2W1, Canada.

${ }^{13}$ Hokkaido University, Faculty of Environmental Earth Science, Sapporo, 060-0810, Japan.

${ }^{14}$ Department of Methodology \& Statistics, Utrecht University, 3584 CH Utrecht, The Netherlands.

$\dagger$ Present addresses: Rubenstein School of Environment and Natural Resources, University of Vermont, Burlington, Vermont 05405, USA (N.J.S., A.T.C.); Asian School of the Environment, Nanyang Technological University, 50 Nanyang Avenue, Singapore 639798 (D.A.W.).

Temperature is a primary driver of the distribution of biodiversity as well as of ecosystem boundaries $^{1,2}$. Declining temperature with increasing elevation in montane systems has long 
been recognized as a major factor shaping plant community biodiversity, metabolic processes, and ecosystem dynamics ${ }^{3,4}$. Elevational gradients, as thermoclines, also enable prediction of long-term ecological responses to climate warming ${ }^{5-7}$. One of the most striking manifestations of increasing elevation is the abrupt transitions from forest to treeless alpine tundra ${ }^{8}$. However, whether there are globally consistent above- and belowground responses to these transitions remains an open question ${ }^{4}$. To disentangle the direct and indirect effects of temperature on ecosystem properties, here we evaluate replicate treeline ecotones in seven temperate regions of the world. We find that declining temperatures with increasing elevation did not affect tree leaf nutrient concentrations, but did reduce ground-layer community-weighted plant nitrogen, leading to strong stoichiometric convergence of ground-layer plant community nitrogen to phosphorus ratios across all regions. Further, elevation-driven changes in plant nutrients were associated with changes in soil organic matter content and quality (carbon to nitrogen ratios) and microbial properties. Combined, our identification of direct and indirect temperature controls over plant communities and soil properties in seven contrasting regions suggests that future warming may disrupt the functional properties of montane ecosystems, particularly where plant community reorganization outpaces treeline advance.

Montane ecosystems are undergoing and will continue to undergo rapid changes as global temperatures rise. These ecosystems are critical for maintaining global patterns of biodiversity and ecosystem functioning, but we know little about whether disparate montane regions around the world will change in similar and predictable ways. Globally, mountain ecosystems differ in geological age, relative land area, historical disturbances, climatic regimes, topographic complexity, and species composition. However, the most universally consistent and biologically influential effect of increasing elevation is an adiabatic decline in temperature ${ }^{9}$. Declining temperature has an overarching influence over vegetation responses along elevational gradients ${ }^{4,9}$, including one of the most visually striking effects of decreasing temperatures: the formation of treelines ${ }^{9}$. The most plausible explanation for treeline formation, the growth limitation hypothesis, posits that declining carbon sink strength at treelines, rather than declining carbon supplied from photosynthesis, results from the direct effect of low temperatures on metabolic processes essential for wood production ${ }^{8,10}$. As a result of low temperatures, treesregardless of taxon—-form treeline ecotones within a narrow and globally consistent isotherm 
with mean growing season temperatures of $6.7-7^{\circ} \mathrm{C}$ wherever growing seasons are at least three months long ${ }^{10}$. Because of this global thermocline, the position and dynamics of ecosystem properties near treelines have the potential to act as a powerful signal of the cascading effects of climate change $e^{4}$.

In addition to reduction of tree growth and loss of trees, other ecological properties are driven by elevation-associated temperature declines. For instance, leaf nutrient concentrations can decline ${ }^{11,12}$, stay consistent, or even increase with increasing elevation ${ }^{9}$. This suggests that processes associated with nutrient availability, communities of soil microbes that regulate plant nutrient supply, and plant nutrient demands could all indirectly contribute to ecosystem properties as second-order drivers after the effects of treeline position and plant community properties are considered ${ }^{13,14}$.

In this study we asked how elevation-mediated temperature directly and indirectly affects the nutrient status of plant communities, if there are coupled responses of above- and belowground properties with temperature, and if patterns and processes are consistent across biotic community transitions in seven disparate montane regions globally. We measured ecosystem properties across multiple treeline ecotones to permit regional standardization of growing season temperatures because treelines occur at similar air temperature thresholds (Supplementary Methods). For each of five (or, in one case, four) replicate transects in each region, we sampled at six elevations: 150 and $50 \mathrm{~m}$ below the treeline, just below and just above the treeline, and 50 and $150 \mathrm{~m}$ above the treeline; elevational ranges represented $\sim 2{ }^{\circ} \mathrm{C}$ isoclines ${ }^{10}$ (Supplementary Methods). The regions differed in geological age (1-400 Myr), climate (Supplementary Table 1), and floristic composition (Supplementary Table 2), yet all treelines exhibited characteristic responses to declining temperatures, including a decline in tree height and stand basal area, an increase in stem density (Extended Data Fig. 1a-c and Supplementary Table 3), and the formation of distinct treeline ecotones (Extended Data Fig. 2). Our regionally replicated approach enabled us to test (1) if the concentrations of potentially growth limiting nitrogen $(\mathrm{N})$ and phosphorus $(\mathrm{P})$, and their ratio, in the foliage of trees and ground-layer plants, and in roots, consistently covary with decreasing temperature among regions, despite differences in biotic communities and regionally specific factors ${ }^{4}$; and (2) whether these patterns in plant nutrient concentrations are tightly coupled to soil nutrient availability and/or microbial community structure. 
Because plant $\mathrm{N}$ to $\mathrm{P}$ ratios (hereafter N/P; mass basis) can provide insight into relative nutrient limitations ${ }^{15}$, we compared variation in both above- and belowground N/P across the 34 transects in the seven regions using linear mixed-effect modelling (Fig. 1). Although standweighted foliar N/P in trees was regionally variable, it did not vary consistently with elevation (Fig. 1a), reflecting little to no variation in tree $\mathrm{N}$ or $\mathrm{P}$ with elevation (Extended Data Fig. 1d, e and Supplementary Table 4) because of either species turnover or intraspecific variation (Supplementary Table 5). Our results are consistent with evidence that nutrients are not involved in treeline formation ${ }^{9}$, because previous research suggests treeline is primarily driven by temperature effects on the carbon $(C)$ source-sink balance ${ }^{9,10,16}$. Previous work has shown tree $\mathrm{N} / \mathrm{P}$ to increase with temperature across large latitudinal gradients ${ }^{17}$, but such an increase was not detected here, probably because our study focused on a specific ecosystem type containing a much narrower range of temperatures.

Despite fourfold variation in community-level foliar N/P for ground-layer plants among regions, N/P universally converged at the highest elevations (Fig. 1b), as indicated by the crossregional sharp decline in coefficients of variation with increasing elevation (coefficient of variation dropping from 42 to 18 over a $300 \mathrm{~m}$ elevational increase, $R^{2}=0.79$; Extended Data Fig. 3a). This convergence across disparate regions suggests a universal stoichiometric optimum for $\mathrm{N}$ and $\mathrm{P}$ at low temperatures (that is, average $\mathrm{N} / \mathrm{P}$ of $11.5 \pm 0.32$ at $150 \mathrm{~m}$ above treelines). By contrast, the coefficient of variation of fine root N/P was greatest just above the treeline (Extended Data Fig. 3b) and N/P of soil nutrient pools remained variable at high elevations (Fig. 1c-e). Stoichiometric convergence (that is, significant decline in the coefficient of variation with increasing elevation) for foliage of ground-layer plant communities occurred above treelines despite regionally consistent declines in both foliar and root $\mathrm{N}$ and $\mathrm{P}$ by roughly 20-30\% (Supplementary Tables 4 and 6 and Extended Data Fig. 4). The decline in foliar N occurred despite expectations that colder temperatures and higher irradiance would increase mass-based foliar $\mathrm{N}$ due to either soil $\mathrm{N}$ availability exceeding plant demand ${ }^{18}$ or cold-induced increases in plant $\mathrm{N}^{19}$. The observed stoichiometric convergence with increasing elevation cannot be explained by convergence in either taxonomic or phylogenetic composition of plant communities (Extended Data Figs 5-7). Instead, our results indicate that among-region variation in plant community N/P, and the factors that contribute to that variation, diminish as elevation increases because of increasing constraints imposed by cold temperatures. This effect of low temperatures 
may arise from consistent nutrient limitation in cold-stressed high-elevation ground-layer plant communities $^{15}$, or from stoichiometric rebalancing of N-rich proteins and P-rich RNA in the plants composing these communities ${ }^{20}$.

Spatial variation in plant $\mathrm{N}$ and $\mathrm{P}$ concentrations should reflect the availability of growth limiting soil nutrients, particularly in cold environments ${ }^{13}$. Therefore, soil and plant nutrients should be tightly coupled across treeline elevational gradients because cold temperatures reduce water viscosity, cell membrane permeability, and microbial mineralization of $\mathrm{N}$ and $\mathrm{P}^{11}$, although this has not been widely explored ${ }^{4,21}$. Because many of the processes we examined varied among regions (Supplementary Table 4), we assessed whether ground-layer plant, root, and soil $\mathrm{N}$ and $\mathrm{P}$ were coupled within regions and whether that coupling varied systematically with changing elevation and across treeline ecotones. While there was considerable variability in the extent of coupling among regions (Fig. 2), a consistent pattern of parallel declines in groundlayer plant foliar $\mathrm{N}$ and $\mathrm{P}$ emerged (Fig. 2a, d): ground-layer foliar $\mathrm{N}$ and $\mathrm{P}$, while tightly correlated with one another across all elevational gradients $\left(R_{\mathrm{c}}^{2}=0.82\right)$ when regional variance was accounted for), were each better explained by including at least one metric of soil $\mathrm{N}$ or $\mathrm{P}$ (Fig. 2b, c, e, f and Supplementary Table 7). Thus, when combined with the uncertainty or delay in treeline migration ${ }^{22}$, the strong response of these ecosystem properties to forest cover in many regions (Fig. 2) suggests that ongoing climatic warming may result in a decoupling of soil $\mathrm{N}$ and $\mathrm{P}$ cycles in both ground-layer vegetation and soil ${ }^{21}$. A divergence, rather than convergence, of

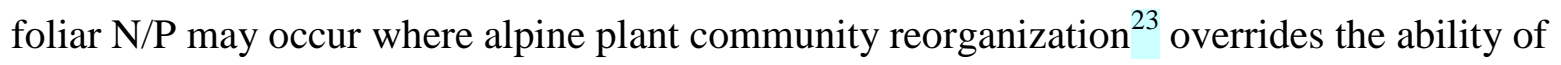
plants to adjust their stoichiometry ${ }^{24}$, and/or when filtering of plant communities by soil nutrients $\operatorname{occurs}^{25}$, with potential cascading effects on ecosystem processes ${ }^{21}$.

There are many direct and indirect pathways by which changes in temperature might affect ecosystem properties, including plant nutrient optimization, plant-soil feedbacks, and shifts in microbial community structure and activity, and their effects on plant nutrient availability $^{11}$. We used a structural equation modelling (SEM) framework to disentangle the direct and indirect effects of changes in elevation-dependent temperature on ecosystem properties (Fig. 3a). The best-fitting model revealed that temperature both directly and indirectly influenced community-weighted foliar and root N (Fig. 3b). Subsequent comparisons using standardized total and indirect effects indicated that plant $\mathrm{N}$ pools were most affected by the direct effects of declining temperature (Supplementary Table 8). In contrast, ground-layer plant 
foliar and root $\mathrm{P}$ were exclusively driven by the indirect effect of temperature on foliar and root $\mathrm{N}$ (Supplementary Table 8), not by soil P availability (that is, Bray or total P; Fig. 3b). Thus, the coupling of ground-layer plant, root, and soil $\mathrm{N}$ and $\mathrm{P}$ pools among regions results from the stoichiometric rebalancing of tissue $\mathrm{P}$ in response to declining tissue $\mathrm{N}$ with decreasing temperatures. The SEM also highlights how the effects of temperature on the quantity and quality (for example, $\mathrm{C} / \mathrm{N}$ ) of soil organic matter (SOM) are mediated by the cascading influence of tree cover on soil and microbial properties (Supplementary Table 9 and Extended Data Figs 8 and 9).

Our analyses indicate that, despite geographical variation, ongoing and likely future migration of lower elevation plant species to higher elevations ${ }^{26}$ will lead to ground-layer plant communities with higher foliar nutrients and potentially accelerated nutrient cycles ${ }^{21}$. However, community-level variation in ground-layer plant foliar nutrients with temperature could arise from changes in species composition or within-species variation. Here, the contribution of species turnover in understorey plant communities was more important than intraspecific variation, for both community-weighted foliar $\mathrm{N}$ (mean variance explained 22.7 versus $7.3 \%$, respectively) and $\mathrm{P}$ (mean variance explained 26.7 versus $9.7 \%$, respectively). Additionally, the variance explained by elevation was larger than that explained by the presence versus absence of tree cover for both $\mathrm{N}$ (mean variance explained 16.8 versus $4.8 \%$ ) and $\mathrm{P}$ (mean variance explained 20.0 versus $5.1 \%$ ) (Fig. 4).

Temperature shapes plant physiological and community properties, and ecosystem dynamics and boundaries ${ }^{9,19}$. Previous work shows that plant nutrients and associated ecophysiological traits vary systematically with temperature across large latitudinal ${ }^{17}$ and elevational ${ }^{6}$ gradients. Our findings advance previous work by demonstrating broadly consistent responses of community-level $\mathrm{N}$ for ground-layer plants to increasing elevation and declining temperature, resulting in strong convergence of N/P despite large variation in both biotic and abiotic factors among different temperate mountain regions globally. Further, these elevationdriven changes in plant nutrients were associated with clear changes in SOM content and quality (C/N ratios) and microbial properties (Fig. 3). Finally, our identification of direct and indirect temperature controls over plant and microbial communities in seven distinct regions worldwide suggests that warming could disrupt the functional properties of montane ecosystems and result 
in periods of disequilibrium ${ }^{27,28}$ where plant-soil feedbacks are partly decoupled under warmer conditions $^{29,30}$.

Received 21 June; accepted 28 November 2016.

Published online XX 2016.[Nature proofreader: please update when known.]

1. von Humboldt, A. Aspects of Nature, in Different Lands and Different Climates; with Scientific Elucidations, Vol. II (Longman, Brown, Green, Longmans, John Murray, 1849

2. Whittaker, R. H. Vegetation of the Great Smokey Mountains. Ecol. Monogr. 26, 1-80 (1956).

3. Graham, C. H. et al. The origin and maintenance of montane diversity: integrating evolutionary and ecological processes. Ecography 37, 711-719 (2014).

4. Sundqvist, M. K., Sanders, N. J. \& Wardle, D. A. Community and ecosystem responses to elevational gradients: processes, mechanisms, and insights for global change. Annu. Rev. Ecol. Syst. 44, 261-280 (2013).

5. Dunne, J. A., Saleska, S. R., Fischer, M. L. \& Harte, J. Integrating experimental and gradient methods in ecological climate change research. Ecology 85, 904-916 (2004).

6. Asner, G. P. et al. Amazonian functional diversity from forest canopy chemical assembly. Proc. Natl Acad. Sci. USA 111, 5604-5609 (2014).

7. Pepin, N. et al. Elevation-dependent warming in mountain regions of the world. Nature Clim. Chang. 5, 424-430 (2015).

8. Körner, C. A re-assessment of high elevation treeline positions and their explanation. Oecologia 115, 445-459 (1998).

9. Körner, C. Alpine Treelines: Functional Ecology of the Global High Elevation Tree Limits (Springer, 2012).

10. Hoch, G. \& Körner, C. Global patterns of mobile carbon stores in trees at the highelevation tree line. Glob. Ecol. Biogeogr. 21, 861-871 (2012).

11. Loomis, P. F., Ruess, R. W., Sveinbjörnsson, B. \& Kielland, K. Nitrogen cycling at treeline: latitudinal and elevational patterns across a boreal landscape. Ecoscience 13, 544-556 (2006). 
12. Vitousek, P. M., Matson, P. A. \& Turner, D. R. Elevational and age gradients in Hawaiian montane rainforest: foliar and soil nutrients. Oecologia 77, 565-570 (1988).

13. Thébault, A. et al. Nitrogen limitation and microbial diversity at the treeline. Oikos 123, 729-740 (2014).

14. Davis, J., Schober, A., Bahn, M. \& Sveinbjörnsson, B. Soil carbon and nitrogen turnover at and below the elevational treeline in northern Fennoscandia. Arct. Alp. Res. 23, 279286 (1991).

15. Güsewell, S. N. P ratios in terrestrial plants: variation and functional significance. New Phytol. 164, 243-266 (2004).

16. Fajardo, A. \& Piper, F. I. An experimental approach to explain the southern Andes elevational treeline. Am. J. Bot. 101, 788-795 (2014).

17. Reich, P. B. \& Oleksyn, J. Global patterns of plant leaf N and P in relation to temperature and latitude. Proc. Natl Acad. Sci. USA 101, 11001-11006 (2004).

18. Wright, I. J. et al. Modulation of leaf economic traits and trait relationships by climate. Glob. Ecol. Biogeogr. 14, 411-421 (2005).

19. Woods, H. A. et al. Temperature and the chemical composition of poikilothermic organisms. Funct. Ecol. 17, 237-245 (2003).

20. Elser, J. J., Fagan, W. F., Kerkhoff, A. J., Swenson, N. G. \& Enquist, B. J. Biological stoichiometry of plant production: metabolism, scaling and ecological response to global change. New Phytol. 186, 593-608 (2010).

21. Yuan, Z. Y. \& Chen, H. Y. H. Decoupling of nitrogen and phosphorus in terrestrial plants associated with global changes. Nature Clim. Chang. 5, 465-469 (2015).

22. Harsch, M. A., Hulme, P. E., McGlone, M. S. \& Duncan, R. P. Are treelines advancing? A global meta-analysis of treeline response to climate warming. Ecol. Lett. 12, 10401049 (2009).

23. Greenwood, S. \& Jump, A. S. Consequences of treeline shifts for the diversity and function of high altitude ecosystems. Arct. Antarct. Alp. Res. 46, 829-840 (2014). 
24. Sistla, S. A. \& Schimel, J. P. Stoichiometric flexibility as a regulator of carbon and nutrient cycling in terrestrial ecosystems under change. New Phytol. 196, 68-78 (2012).

25. $\mathrm{Yu}, \mathrm{Q}$. et al. Stoichiometric homeostasis predicts plant species dominance, temporal stability, and responses to global change. Ecology 96, 2328-2335 (2015).

26. Gottfried, M. et al. Continent-wide response of mountain vegetation to climate change. Nature Clim. Chang. 2, 111-115 (2012).

27. Ernakovich, J. G. et al. Predicted responses of arctic and alpine ecosystems to altered seasonality under climate change. Glob. Change Biol. 20, 3256-3269 (2014).

28. Svenning, J.-C. \& Sandel, B. Disequilibrium vegetation dynamics under future climate change. Am. J. Bot. 100, 1266-1286 (2013).

29. Peñuelas, J. et al. Human-induced nitrogen-phosphorus imbalances alter natural and managed ecosystems across the globe. Nature Commun. 4, 2934 (2013).

30. Wookey, P. A. et al. Ecosystem feedbacks and cascade processes: understanding their role in the responses of Arctic and alpine ecosystems to environmental change. Glob. Change Biol. 15, 1153-1172 (2009).

Supplementary Information is available in the online version of the paper.

Acknowledgements We thank Y. Amagai, B. Andersson, C. Arnoldi, P. Bellingham, A. Boily, B. Case, G. Crutsinger, M. Dawes, W. Gilliam, K. Gundale, N. Hendershot, H. Hall, M. Hotter, J. Lundholm, P. Manning, C. McClure, Q. Read, B. Roskilly, A. Shimokawabe, D. Stöhr, and B. Turner for laboratory, logistical, or field assistance. This work was made possible by a Wallenberg Scholars Award to D.A.W.; regional support from Fondecyt 1120171 to A.F.; a National Science Foundation Dimensions of Biodiversity grant (NSF-1136703), a grant from the Carlsberg Fund, and support from the Danish National Research Foundation to the Center for Macroecology, Evolution, and Climate to N.J.S.; a US Department of Energy, Office of Science, Office of Biological and Environmental Research, Terrestrial Ecosystem Sciences Program Award (DE-SC0010562) to A.T.C.; support from the UK Natural Environment Research Council to R.D.B.; support from the BiodivERsA project REGARDS (ANR-12-EBID-004-01) to J.-C.C., S.L., K.G. and REGARDS (FWF-I-1056) to M.B.; and, support from the Natural Sciences and Engineering Research Council of Canada to Z.G.

Author Contributions R.D.B., A.T.C., N.J.S., S.L., J.R.M., M.S., and D.A.W. designed the study; D.A.W. acquired the funding needed to initiate the study; J.-C.C., D.O., C.C., and M.K.S. provided specialized laboratory or statistical assistance; J.R.M. oversaw field work in each region with R.D.B., M.B., A.T.C., E.C., A.F., K.G., Z.G., G.K., S.L., 
N.J.S., M.K.S., and D.A.W. contributing to subsets of field sampling; J.R.M. wrote the first draft of the manuscript in close consultation with D.A.W., and all authors contributed to manuscript completion and revision.

Author Information Reprints and permissions information is available at www.nature.com/reprints. The authors declare no competing financial interests. Readers are welcome to comment on the online version of the paper. Correspondence and requests for materials should be addressed to J.R.M. (clavulina@ gmail.com).

Reviewer Information Nature thanks M. Macias-Fauria and the other anonymous reviewers for their contribution to the peer review of this work.

Figure 1 Ecosystem N/P from seven temperate regions in relation to elevation from treeline. Smoothing curves illustrate trends for each of the seven regions; symbols represent individual plots. Significant fixed effects of region $(R)$, elevation from treeline $(E)$, vegetative community ( $V$, forest or alpine), and their interactions are given to the right of each figure on the basis of linear mixed-effect models $* P<0.05, * * P<0.001$, *** $P<0.0001$. a, Basal-area-weighted tree foliar N/P ( $n=101$ plots) remained uniform within, but distinct across, regions. b, Coverweighted ground-layer plant foliar N/P ( $n=202$ plots) exhibited multiple interactions because it varied widely among regions at low elevations and converged globally to a mean of $11.50 \pm 0.32$ at elevations $150 \mathrm{~m}$ above treeline (Supplementary Fig. 3a). c, Root N/P ( $n=200$ plots) varied across regions; variability among regions was highest just above treeline and then declined with elevation above treeline (Supplementary Fig. 3b). d, Soil surface total N/P ( $n=203$ plots) varied

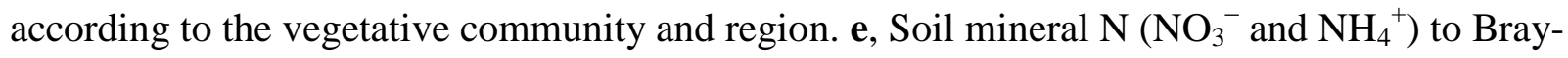
extractable $\mathrm{P}$ ratios (which serve as metrics of the ratio of bioavailable $\mathrm{N}$ relative to $\mathrm{P} ; n=203$ plots) showed variable responses to elevation-associated temperature depending on both vegetation type and region as indicated by a significant effect of region $\times$ vegetative community $\times$ elevation from treeline.

\section{Figure 2 Ecosystem patterns among specific plant and soil $\mathrm{N}$ and $\mathrm{P}$ pools along the} elevational gradients. Significant fixed effects of elevation from treeline $(E)$, vegetative community ( $V$, forest or alpine), or their interaction based on a linear mixed-effect models are given ( $n=30$ plots except for 24 in Hokkaido and 27 in Australia). $\dagger P \leq 0.10, * P<0.050$, $* * P<0.001, * * * P<0.0001$. a, Cover-weighted foliar $\mathrm{N}$ concentration [cwN] (mass basis) for ground-layer vegetation. b, Soil C/No. c, Soil mineral $\mathrm{N}$ concentration $\left(\mathrm{NO}_{3}{ }^{-}\right.$and $\left.\mathrm{NH}_{4}{ }^{+}\right)$ represented on an area basis. d, Cover-weighted foliar P concentration [cwP] for ground-layer vegetation. e, Soil C/P. f, Bray-extractable soil $[\mathrm{P}]$ represented on an area basis. The seven 
regions are arranged in order from low to high foliar N. Roots, which strongly correlate with foliage, are omitted for brevity. Smoothing curves illustrate trends within each of the seven regions and general coupling of plant and soil nutrient metrics with the exception of Hokkaido, Japan, which was dominated by dwarf pine above most treelines.

Figure 3 Representations of cascading relationships among above- and belowground ecosystem components to elevation-associated temperature effects. a, General conceptual metamodel of potential pathways by which temperature (in grey) could affect forest tree basal area (orange), microbial properties (bright blue), soil fertility and nutrient availability (light green), and plant nutrient status (dark green) through direct and indirect pathways. Actual measured indicator variables for each hypothetical metamodel group are in white boxes, where plant nutrients refer to cover-weighted values of ground-layer vegetation and total root nutrients. SIR, substrate-induced respiration; PLFA, phospholipid fatty acid; RDA, redundancy analysis. b, Best-supported SEM illustrating the major direct and indirect pathways through which elevationassociated temperature drives variation in ecosystem properties among treeline transition zones of our study regions $\left(\chi^{2}=239.037\right.$, d.f. $\left.=49, P=0.076\right)$. Arrows represent direct and indirect flows of causality from elevation-associated temperature to plant nutrient status. Arrow width is proportional to the standardized coefficient estimates (numbers accompanying each arrow) and can be interpreted as the relative importance and direction of the relationship between a variable and all variables upstream of that arrow. Solid arrows indicate significance at $* P<0.05$, dashed arrows indicate non-significant coefficient estimates, and grey arrows indicate modelled covariance.

\section{Figure 4 Decomposition of the total variability in cover-weighted foliar $\mathbf{N}$ and $\mathbf{P}$} concentrations (cwN, cwP) (mass basis) for the ground-layer plant community. Variance associated with elevation from treeline (elevation), vegetative community (that is, forest or alpine), and their interaction in each of seven temperate regions are given. Shaded bars indicate the percentage of relative variation explained by turnover of species, intraspecific variability, and their covariation along the elevational gradients on the basis of sum of squares decomposition. Bold black lines represent total explained variation or, if below bar totals (Hokkaido), negative covariation. Red asterisks indicate significance at $P \leq 0.05$ and red dagger symbols indicate marginal significance at $P \leq 0.10$. Indicators to the right of shaded bars indicate significance of 
total variation. Australia was unique as it had a greater proportion of explained variance associated with intraspecific (that is, within-species) variation than with species turnover, and because it showed strong interactive effects caused by higher within-species flexibility with elevation in the forest relative to above the treeline.

\section{METHODS}

\section{Research design}

To examine how changes in relatively uniform elevation-associated temperatures and vegetative community transitions influence above- and belowground ecosystem properties, we sampled across replicate elevational gradients spanning temperate treeline ecotones in seven regions of the world (Supplementary Table 1). In each, we evaluated the nutrient concentrations in leaves and roots of the dominant vegetation, nutrient pools in surface soils, aspects of soil fertility, and several microbial properties (for example, biomass, community structure, and activity). We sampled elevational gradients from temperate latitudes $\left(36-50^{\circ} \mathrm{N}\right.$ or $\left.\mathrm{S}\right)$, thus avoiding possible complications associated with tropical climates (for example, diminishing incident radiation due to increasing fog or increasing precipitation with elevation) ${ }^{9}$, and degree of relative soil weathering at tropical latitudes ${ }^{17,31}$

Five replicate transects were established in each of the seven regions (except for four in Hokkaido, Japan, owing to logistic limitations) in the mid- to late-growing season between July 2013 and August 2014 and December 2013 to January 2015 for the Northern or Southern Hemispheres, respectively. Precise dates for each region were chosen to ensure that plants were in full leaf yet not senescing due to drought stress or phenology; these were selected on the basis of expert recommendation and the availability of collaborators working in that region. Each transect consisted of six radial plots $\left(314 \mathrm{~m}^{2}\right.$ each) positioned at six different elevations relative to the treeline: that is, as close as possible to $150 \mathrm{~m}$ and $50 \mathrm{~m}$ above the treeline, just above and below the treeline, and $50 \mathrm{~m}$ and $150 \mathrm{~m}$ below the treeline. Elevation for each plot was recorded using a Garmin GPS equipped with a locally calibrated barometric altimeter. Because there was some variation in how close we could position plots to the desired elevation owing to topographic constraints, elevation relative to treeline was best represented as a continuous explanatory variable. Centring transects on treeline permitted direct comparisons of the same temperature ranges across regions, because treelines form where growing seasons greater than 3 
months have average air temperatures between approximately $6.6-7{ }^{\circ} \mathrm{C}$ in both Northern and Southern Hemispheres ${ }^{10,32}$. Evidence for a remarkably similar average treeline temperature was derived from temperature sensors deployed across about 50 sites (including in several of the regions and four of the sites included in our study) for a period of 1-3 years (ref. 33). Assuming a global environmental temperature lapse rate of about $6.5^{\circ} \mathrm{C}$ per $1,000 \mathrm{~m}$ of altitudinal increase $^{34}$, an elevational transect of $300 \mathrm{~m}$ (such as is represented by each transect) corresponds to an approximate $2{ }^{\circ} \mathrm{C}$ range of growing-season air temperatures (that is, ranging from roughly $5.9^{\circ} \mathrm{C}$ to $8.1^{\circ} \mathrm{C}$ in our data set if treeline positions are fixed at $7{ }^{\circ} \mathrm{C}$ ). Actual temperature ranges experienced by plants and soils may vary where air moisture interacts with surface processes ${ }^{35}$ or where bare soils in alpine zones are warmed by greater light exposure ${ }^{9}$.

Transects were placed in representative vegetation in each region using satellite imagery and local expertise, taking care to avoid recent disturbances or geomorphic conditions that could topographically suppress natural treeline position (for example, landslides or abrupt slope transitions). We took particular care to ensure that we were sampling treelines that were formed as a consequence of cold temperatures and not those that were formed by other factors, given the focus of our study on vegetation responses to elevation-driven variation in temperature and on predicting responses to climate change. Treeline was defined as the elevation at which there was an abrupt transition from relatively contiguous canopied forests comprising trees $(>3 \mathrm{~m}$ in height) to communities comprising low-statured shrubby vegetation characteristic of alpine tundra $^{36}$ (Extended Data Fig. 2 and Supplementary Table 2). In each of the three lowest elevation forested plots per transect, several measurements were made to quantify tree structure. Forest tree heights were measured from five representative trees in each plot using a Suunto clinometer or a TruePulse 200 laser range finder. Diameter at breast height was recorded for all trees in each plot and each species identified.

In some regions, diffuse treelines required plots be placed in outlying 'tree islands' if they were of a sufficient size to accommodate entire sample plots (that is, they had to be $>314$ $\mathrm{m}^{2}$ ) and represented overall treeline position within the immediate area. Diffusivity of treelines, a metric of the patchiness of tree islands near treeline ${ }^{37}$, varied among regions from relatively diffuse in Australia and Colorado, to abrupt in Chile and New Zealand. This diffusivity probably depended on both the physiological sensitivity of particular tree taxa and transect slope. For instance, Nothofagus spp. form abrupt treelines, and the slope of individual gradients can modify 
treeline abruptness because steep gradients can contain narrower transition zones than more gentle slopes ${ }^{9}$.

In sum, plot establishment resulted in a total of 203 plots in 34 transects: that is, 30 plots (five transects $\times$ six elevations) in each region, except for Hokkaido where only four transects were used, and the Kosciuszko Mountains of Australia where one forest plot in one of the five transects was recently burned.

\section{Soil and microbial analyses}

To characterize biotic and abiotic soil properties, volumetric soil cores $(2.1 \mathrm{~cm}$ inside diameter, $7.5 \mathrm{~cm}$ depth) were taken from eight random locations in each circular plot, homogenized, and passed through a $4 \mathrm{~mm}$ sieve after removal of coarse roots and macrofauna. Soils were expressshipped from each region and refrigerated at $4{ }^{\circ} \mathrm{C}$ before extraction or drying in Umeå, Sweden. Field moist soil subsamples were extracted with $1 \mathrm{M} \mathrm{KCl}$ for mineral nutrient $\left(\mathrm{NO}_{3}{ }^{-}, \mathrm{NH}_{4}{ }^{+}\right)$ concentrations, filtered, and frozen until colorometrically analysed using an Auto-Analyzer III (Omni Process, Solna, Sweden). Total soil C, N, soil pH, and SOM were analysed at the Université Grenoble Alpes, Laboratoire d'Ecologie Alpine, Grenoble, France. Total C and N concentrations were measured from dried and finely ground soil subsamples $\left(60^{\circ} \mathrm{C}, 48 \mathrm{~h}\right)$ by dry combustion using a Flash EA 1112 elemental analyser (Fisher Scientific, Waltham, Massachusetts, USA). SOM was measured from dried and ground soil subsamples by combustion at $550{ }^{\circ} \mathrm{C}$ for $4 \mathrm{~h}$ in a muffle furnace, and comparison with total $\mathrm{C}$ revealed negligible inorganic C. Soil $\mathrm{pH}$ was measured on dried soils using a 1:4 (soil:distilled water) solution. Total and 'available' P concentrations were analysed in the Biogeochemistry Laboratory of the Smithsonian Tropical Research Institute in Panama City, Panama. Dried soil subsamples were analysed for total $\mathrm{P}$ by combustion at $550{ }^{\circ} \mathrm{C}$ for $1 \mathrm{~h}$ in a muffle furnace, digestion in $1 \mathrm{M}$ sulfuric acid, and quantification of orthophosphate by automated molybdate colorimetry $^{38}$. Bray-extractable $\mathrm{P}$, a metric of bioavailable $\mathrm{P}$, was measured from dry soil subsamples using Bray-1 solution $\left(0.03 \mathrm{~N} \mathrm{NH}_{4} \mathrm{~F}\right.$ in $\left.0.025 \mathrm{~N} \mathrm{HCl}\right)$ and quantification by automated molybdate colorimetry ${ }^{39}$. Because bulk densities varied widely across the gradients, soil total and extractable $\mathrm{N}$ and $\mathrm{P}$ concentrations were represented on an area basis (for example, kilograms per hectare) derived from one of nine potentially representative volumetric soil cores taken from each plot. 
Substrate-induced respiration (SIR; a relative measure of active soil microbial biomass $^{40,41}$ ) was measured for a $10 \mathrm{~g}$ subsample of each soil sample. Before analysis, the moisture content of each sample was specifically adjusted to a constant level for each region to accommodate the large differences in SOM contents among regions. Each subsample was amended with $20 \mathrm{mg}$ glucose, placed in a $130 \mathrm{~mL}$ airtight vessel, and incubated at $22{ }^{\circ} \mathrm{C}$ for $3 \mathrm{~h}$. Evolution of $\mathrm{CO}_{2}$ between $1 \mathrm{~h}$ and $3 \mathrm{~h}$ was then determined by injecting $1 \mathrm{~mL}$ subsamples of headspace gas into an EGM-4 environmental gas $\mathrm{CO}_{2}$ analyser (PP systems).

We also measured the composition of microbial phospholipid fatty acids (PLFAs) to assess the microbial community on a $1 \mathrm{~g}$ subsample of each soil sample; different PLFAs represent different subsets of the soil microflora. For each soil subsample, PLFA abundance was expressed as relative nanomoles per gram using standard nomenclature ${ }^{42}$. The PLFAs used to

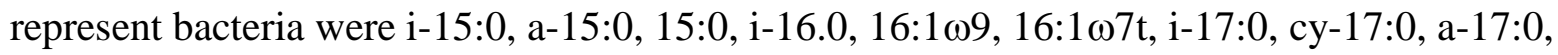

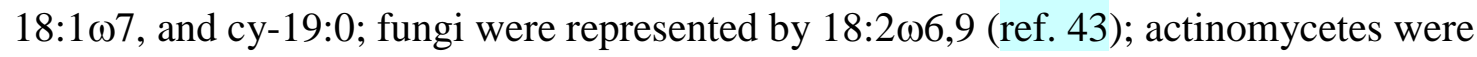
represented by 10Me17:0 and 10Me18:0 (ref. 44); and the sum of these represented total microbial PLFAs.

\section{Plant foliar and root analyses}

Plant material $\mathrm{N}$ and $\mathrm{P}$ concentrations were measured from healthy green leaves collected from all tree species, the most abundant ground level plant species, and live fine roots in each plot. Fine roots $(<2 \mathrm{~mm})$ were collected while processing the eight $7.5 \mathrm{~cm}$ deep soil cores taken from each plot and thus represent a composite of all plant species with roots present in surface soils. This includes trees plus ground-layer plants below the treeline and only ground-layer plants above the treeline. Tree foliar nutrients were measured in each plot on samples from up to five individuals of each species using a pole-pruner at heights up to $5 \mathrm{~m}$. Only sub-canopy tree leaves were taken to reduce potential bias associated with relatively higher $\mathrm{N}$ contents ${ }^{45}$ of highly sunexposed foliage in low-statured forested plots near treeline. All plant material was dried $\left(60{ }^{\circ} \mathrm{C}\right.$, $48 \mathrm{~h}$ ), finely ground using a ball mill, and subsamples were decomposed using a Kjeldahl digest $\left(8 \% \mathrm{H}_{2} \mathrm{SO}_{4}\right)$. Total $\mathrm{N}$ and $\mathrm{P}$ concentrations in the digests were analysed using an Omniprocess Lachat Auto-Analyzer at the Swedish University of Agricultural Sciences, SLU, Umeå, Sweden.

Ground-layer plant foliar N and P concentrations were measured on green leaves collected from up to ten healthy individuals of the most abundant species in each plot and 
weighted by percentage cover of that species to get a measure of community-weighted foliar $\mathrm{N}$ and $\mathrm{P}$ for that plot, represented on a mass basis. Analysed plant species represented a diversity of growth forms including woody shrubs, forbs, graminoids, ferns, and mat-forming cushion plants (Supplementary Table 2). Percentage cover was derived from high-resolution photographs of 1214 gridded vegetation quadrats $\left(0.5 \mathrm{~m}^{2}\right)$ randomly arrayed within the circular plot (about 2,500 vegetation quadrats sampled in total), and vascular plant species' abundance later scored using a modified Braun-Blanquet method ${ }^{46}$ on a large and high-resolution $(60 \mathrm{~cm}, 4 \mathrm{~K})$ computer monitor with five relative abundance classes $(<5 \%, 5-25 \%, 25-50 \%, 50-75 \%,>75 \%$ cover $)$. Foliar N and $\mathrm{P}$ were weighted by cover using the following equation:

$$
\text { weighted plot }- \text { average }=\sum_{i=1}^{n}\left(p_{i} \times\left[\text { nutrient }_{i}\right]\right)(1)
$$

where, $p_{i}$ is the relative cover of species $i$ in the plot and [nutrient ${ }_{i}$ is the concentration of $\mathrm{N}, \mathrm{P}$, or the ratio of $\mathrm{N}$ to $\mathrm{P}$ of species $i^{47,48}$. Understorey plant nutrient concentrations were typically derived from $>80 \%$ of total understorey vascular plant cover and $100 \%$ of tree cover, thus satisfying the criterion set for the weighted average approach ${ }^{48}$. For each plot, tree foliar nutrients were weighted by the relative basal area for each species present to obtain a measure of community-weighted foliar $\mathrm{N}$ and $\mathrm{P}$ in that plot. In total, diameter at breast height from 5,434 stems and foliar nutrients from 13 tree species across the seven regions were measured.

For each country, the total variation in the data sets for N, P, and N/P that was related to elevational changes was decomposed into within-species and across-species variation components using a standard approach ${ }^{49}$. Briefly, this approach decomposes total sum of squares of the plot-level variance related to elevational changes into fixed, intraspecific, and covariation effects to enable statistical evaluation of the relative contribution of species turnover and intraspecific variation to the response of foliar nutrients at the whole community level.

\section{Statistical analyses}

We used a combination of linear and multivariate analyses to examine global and regional patterns in ecosystem properties across treeline ecotones. Data were graphically analysed using JMP 11.2.1 statistical software (SAS Institute, Cary, North Carolina, USA) and tested in the R 3.2.0 statistical environment ${ }^{50}$. All elevation transects were centred on treelines and thus spanned two distinct vegetative communities (that is, subalpine forest below treelines and treeless alpine 
vegetation above). These vegetative communities were coded either as binary categorical values in linear regressions, or as basal area of stems per plot in the SEMs. To improve model fitting and to explicitly incorporate the experimental design, values of elevation were represented as metres of elevation from treeline and were positive above the treeline and negative below it. Our statistical analyses allow separation of the effects of vegetative cover (forest versus alpine), which varies with elevation, from the effects of elevation (temperature) that are independent of whether trees were present.

Linear mixed-effect regression models were fitted using the lme4 package ${ }^{51}$. Each regional transect was treated as a random effect to accommodate any unique clustered variances associated with localized geological or floristic properties specific to that transect within each region. Each response was fit using the fixed effects of region $\times$ vegetative community $\times$ elevation and, given the consistency of regional significance (for example, Supplementary Tables 3, 4 and 9), subsequent models were fitted for each region individually (for example, Fig. 2 and Extended Data Fig. 8). Resulting standardized parameter coefficients for some of these regional tests are given in Supplementary Table 6 for comparison of vegetation and elevation effect sizes. Comparison of model fits with and without soil $\mathrm{N}$ and $\mathrm{P}$ pools and ranked using Akaike information criteria ${ }^{52}$ are given in Supplementary Table 7. Each response variable, and the elevation from treeline explanatory variable, were centred and scaled by two standard deviations to permit direct comparison with the binomial vegetation category (for example, subalpine forest versus alpine communities) ${ }^{53}$ and to allow for interpretation of main effects in the presence of interactions ${ }^{54,55}$. All linear model fits were assessed for violations of normality and heteroscedasticity and $\log , \log +1$, or square-root transformed when necessary. Outliers were assessed using goodness-of-fit tests and coefficients of robust regressions of models compared with original lme4 models using the robustlmm package to confirm that such outliers did not impact model results ${ }^{56}$. Hypothesis testing of explanatory variables was performed using likelihood ratio tests with type III ANOVA Satterthwaite approximation of degrees of freedom in the lmerTest package ${ }^{57}$. Marginal (fixed) and conditional variance

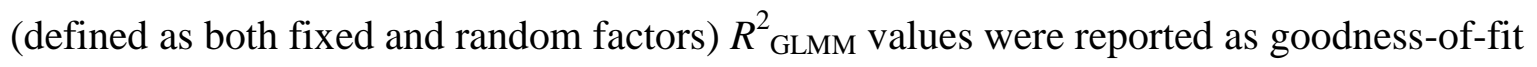
statistics using the MuMIn package ${ }^{58}$ as defined in ref. 59. To evaluate high-elevation convergence of tree, ground level plant, or total root $\mathrm{N}$ and $\mathrm{P}$ concentrations and N/P indicated in Fig. 1, we calculated the coefficient of variation among plots located at each elevational level 
(+150 m, $+50 \mathrm{~m}$, just above and just below treeline, $-50 \mathrm{~m},-150 \mathrm{~m})$ in each region, then used linear regression across elevational levels to assess convergence. Resulting linear fits of the ground level plant and root coefficients of variation are in Extended Data Fig. 3.

To test whether statistically significant responses of coefficients of variation to elevation could be explained by convergence in phylogeny or community composition or by altered dominance across elevations, we performed additional analyses on the full plant community data sets. We used the phylomatic_names function in the branching package 0.1 .0 (ref. 60) to match species names to accepted names in the updated APGIII classification ${ }^{61}$ and generated a dated phylogeny from the angiosperm megatree provided by ref. 62. in Phylomatic ${ }^{63}$. To test for a signal of phylogenetic clustering with elevation, we generated phylogenetic metrics using the ape 3.4 (ref. 64) and picante 1.6-2 (ref. 65) packages. We focused on the standardized effect size of phylogenetic mean-pairwise distance, or net-relatedness index (hereafter NRI), weighted by abundance of each plant species. The NRI describes the degree of phylogenetic clustering of taxa relative to a null expectation that species composition is a random draw from the species pool (999 randomizations). We restricted the species pool for each region to all ground-layer species present within the region and chose to randomize species within samples to maintain sample richness across the null communities. Positive values of NRI denote phylogenetic clustering, while negative values denote phylogenetic evenness. To test for the signal of plant species dominance, we determined whether dominance of individual plant species within communities (defined as $1-\left(1 / \sum p_{i}{ }^{2}\right)$, where $p_{i}$ is the proportion of the $i$ th species) increased with elevation or differed in plant communities above and below treeline. We analysed these indices using mixedeffect linear regressions to determine whether NRI or dominance varied among regions and across elevations. To test for a signal of similarity in community composition, we used taxonomic data for each elevation in each region to construct an abundance-weighted distance matrix using Bray-Curtis dissimilarity. A corresponding abundance-weighted phylogenetic distance matrix was generated using the comdist function in the picante package $1.6-2^{65}$. We then used non-metric multidimensional scaling analysis of phylogenetic distances using the metaMDS function in the vegan package 2.4-0 (ref. 65). We used permutational multivariate analysis of variance (PERMANOVA) with the adonis function in the picante ${ }^{66}$ package to examine differences in community and phylogenetic structure across treeline categories (above versus below). We additionally examined differences in multivariate homogeneity of group dispersions 
(PERMDISP) between treeline category with the betadisper function in the vegan package 2.4-0 (ref. 65). All communities were scaled to relative abundances and homogeneity of group variances was assessed before PERMANOVA analysis. Data manipulation for all phylogenetic and community similarity analyses were performed using the dplyr package 0.4 .3 (ref. 67).

SEMs were also fitted using the lavaan package 0.5-18 (ref. 68). Given the spatially nested experimental design of plots dispersed along transects in regions, clustering was accounted for in the lavaan.survey package ${ }^{69}$. The nominal categorical variable of region was coded as a $K-1$ dummy variable as is characteristic for classical regression ${ }^{70}$. A SEM framework allows us to test different direct and indirect causal hypotheses ${ }^{71}$ governing the pathways by which elevation-associated temperature differences affect plant nutrients. The dependence between observations within transects was accounted for by adjusting the fitted statistics and standard errors of the model for the effects of correlated observations. To perform inference of indirect and total effects, we used a resampling approach ${ }^{72}$ that accounted for individual transects using a clustered bootstrap ${ }^{73}$. As a result, confidence intervals accounted for potential skewness due to the clustering and range restrictions of indirect effects. On the basis of causal relationships known from the literature, a path model was formulated (Fig. 3a) with region dummy (0/1) variables introduced as covariates but not reported in the final SEM (Fig. 3b). Microbial biomass was best represented by a latent variable comprising two PLFA-based biomarker indicators, one for fungal and the other for bacterial biomass. Model fit was then examined through the residuals as well as the overall test of model fit adjusted for clustering effects, which revealed that the effect of elevation-associated changes in temperature differed in Hokkaido, and therefore an interaction variable to account for the interaction of region $\times$ elevation was introduced into the model. After introduction of these changes, an Omnibus test of model fit, which tests the hypothesis that omitted paths were jointly zero and accounts for clustering, could not be rejected $\left(\chi^{2}=239.037\right.$, d.f. $\left.=49, P=0.076\right)$ and additional model fit statistics indicated the final model formulation was reasonably good (root mean square error of approximation $($ RMSEA $)=0.138$, comparative fit index $(\mathrm{CFI})=0.924$, standardized root mean square residual $(\mathrm{SRMR})=0.039)$. Standardized path coefficients were computed according to ref. 74 and are presented in Supplementary Table 8. These coefficients can be interpreted as the change in the dependent variable when the independent variable changes by one standard deviation. 
We used detrended correspondence analysis to assess edge and arch effects ${ }^{75}$ in the PLFA data, followed by redundancy analysis (RDA) to examine the relationship between PLFA biomarkers and soil variables. These analyses were performed to understand how the microbial community responded to elevational gradients and how the microbial community covaried with microbial activity (as measured by SIR) and several soil properties visually identified as responsive to the elevational gradients (that is, total $\mathrm{P}$ (kilograms per hectare), mineral $\mathrm{N}$ to Bray P ratios, C/N, SOM, and pH). The RDA was performed in CANOCO (999 Monte Carlo permutations) to first reduce the dimensionality of microbial PLFA biomarkers to just two axes and then mapped onto multivariate space containing non-redundant soil variables (using forward reduction). Each PLFA was weighted by its error variance, meaning those PLFAs that were best

described by the environmental variables received greater weights in the analysis ${ }^{76}$. Missing data in one or more factors in 25 sites resulted in 178 plot-specific data arrays in the analysis. The first two resulting RDA axes (pH dropped in stepwise model reduction) explained 85.9\% (axis 1) and $93.4 \%$ (axes $1+2$ ), respectively, of the total variation in all species-environment relationships. A strong positive variation of PLFA biomarkers with SOM, driven largely by the Hokkaido data, led us to conduct a second RDA analysis using SOM as a covariate to examine the remaining variance in PLFA biomarkers in relation to the remaining soil properties (Extended Data Fig. 9). The subsequent two RDA axes with SOM as covariate explained 64.0\% (axis 1 ) and $87.2 \%$ (axes $1+2$ ) of the total variation in all species-environment relationships. The responses of the first axes from both RDAs (with and without SOM as a covariate) to region $\times$ elevation $\times$ vegetation were then analysed using linear mixed-effect regression models as described previously and reported in Supplementary Table 9.

\section{Data availability}

All data generated or analysed during this study are included in this published article (and its Supplementary Information) and are available from the corresponding author on reasonable request.

31. Chadwick, O. A., Derry, L. A., Vitousek, P. M., Huebert, B. J. \& Hedin, L. O. Changing sources of nutrients during four million years of ecosystem development. Nature 397, 491-497 (1999). 
32. Cieraad, E., McGlone, M. S. \& Huntley, B. Southern Hemisphere temperate tree lines are not climatically depressed. J. Biogeogr. 41, 1456-1466 (2014).

33. Körner, C. \& Paulsen, J. A worldwide study of high altitude treeline temperatures. $J$. Biogeogr. 31, 713-732 (2004).

34. Beychok, M. Atmospheric lapse rate. The Encyclopedia of Earth http://www.eoearth.org/view/article/170859\%3E (2013).

35. Minder, J. R., Mote, P. W. \& Lundquist, J. D. Surface temperature lapse rates over complex terrain: lessons from the Cascade Mountains. J. Geophys. Res. 115, D14122 (2010).

36. Holtmeier, F.-K. \& Broll, G. Treeline advance - driving processes and adverse factors. Landscape Online 1, 1-32 (2007).

37. Harsch, M. A. \& Bader, M. Y. Treeline form - a potential key to understanding treeline dynamics. Glob. Ecol. Biogeogr. 20, 582-596 (2011).

38. Walker, T. W. \& Adams, A. F. R. Studies on soil organic matter: I. Influence of phosphorus content of parent materials on accumulations of carbon, nitrogen, sulfur and organic phosphorus in grassland soils. Soil Sci. 85, 307-318 (1958).

39. Bray, R. H. \& Kurtz, L. T. Determination of total, organic, and available forms of phosphorus in soils. Soil Sci. 59, 39-46 (1945).

40. Anderson, J. P. E. \& Domsch, K. H. A physiologically active method for the quantification of microbial biomass in soil. Soil Biol. Biochem. 10, 215-221 (1978).

41. Wardle, D. A. Changes in the microbial biomass and metabolic quotient during leaf litter succession in some New Zealand forest and scrubland ecosystems. Funct. Ecol. 7, 346355 (1993).

42. Tunlid, A., Hoitink, H. A. J., Low, C. \& White, D. C. Characterization of bacteria that suppress rhizoctonia damping-off in bark compost media by analysis of fatty acid biomarkers. Appl. Environ. Microbiol. 55, 1368-1374 (1989).

43. Frostegård, Å. \& Bååth, E. The use of phospholipid fatty acid analysis to estimate bacterial and fungal biomass in soil. Biol. Fertil. Soils 22, 59-65 (1996). 
44. Kroppenstedt, R. M. in Chemical Methods in Bacterial Systematics (eds Googfellow, M. \& Minnikin, D. E.) 173-199 (Academic, 1985).

45. Markesteijn, L., Poorter, L. \& Bongers, F. Light-dependent leaf trait variation in 43 tropical dry forest tree species. Am. J. Bot. 94, 515-525 (2007).

46. Mueller-Dombois, D. \& Ellenberg, H. Aims and Methods of Vegetation Ecology (John Wiley, 1974).

47. Kichenin, E., Wardle, D. A., Peltzer, D. A., Morse, C. W. \& Freschet, G. T. Contrasting effects of plant inter- and intraspecific variation on community-level trait measures along an environmental gradient. Funct. Ecol. 27, 1254-1261 (2013).

48. Garnier, E. et al. Plant functional markers capture ecosystem properties during secondary succession. Ecology 85, 2630-2637 (2004).

49. Lepš, J., De Bello, F., Smilauer, P. \& Dolezal, J. Community trait response to environment: disentangling species turnover vs intraspecific trait variability effects. Ecography 34, 856-863 (2011).

50 R Core Team. R: a language and environment for statistical computing (R Foundation for Statistical Computing, 2014

51 Bates, D., Maechler, M., Bolker, B. \& Walker, S. lme4: linear mixed-effects models using Eigen S4. R package version 1.1-7. http://CRAN.R-project.org/package=lme4 (2014).

52. Burnham, K. P. \& Anderson, D. R. Multimodel inference. Sociol. Methods Res. 33, 261304 (2004).

53. Gelman, A. Scaling regression inputs by dividing by two standard deviations. Stat. Med. 27, 2865-2873 (2008).

54. Gelman, A. \& Hill, J. Data Analysis Using Regression and Multilevel/Hierarchical Models (Cambridge Univ. Press, 2007).

55. Engqvist, L. The mistreatment of covariate interaction terms in linear model analyses of behavioural and evolutionary ecology studies. Anim. Behav. 70, 967-971 (2005). 
56. Koller, M. robustlmm: Robust Linear Mixed Effects Models. R package version 1.6. http://CRAN.R-project.org/package=robustlmm\%3E (2014).

57. Kuznetsova, A., Brockhoff, P. B. \& Christianson, R. H. B. lmerTest: tests for random and fixed effects for linear mixed effect models. R package version 2.0-11. http://CRAN.R-project.org/package=lmerTest\%3E (2014).

58. Bartoń, K. MuMIn: Multi-model inference. R package version 1.10.5. http://CRAN.Rproject.org/package=MuMIn\%3E (2014).

59. Nakagawa, S. \& Schielzeth, H. A general and simple method for obtaining $R^{2}$ from generalized linear mixed-effect models. Methods Ecol. Evol. 4, 133-142 (2013).

60. Chamberlain, S. brranching: fetch 'phylogenies' from many sources. R package version 0.1.0. https://CRAN.R-project.org/package=brranching (2015).

61. The Angiosperm Phylogeny Group. An update of the Angiosperm Phylogeny Group classification for the orders and families of flowering plants: APG III. Bot. J. Linn. Soc. 161, 105-121 (2009).

62. Zanne, A. E. et al. Three keys to the radiation of angiosperms into freezing environments. Nature 506, 89-92 (2014).

63. Webb, C. O. \& Donoghue, M. J. Phylomatic: tree assembly for applied phylogenetics. Mol. Ecol. Notes 5, 181-183 (2005).

64. Paradis, E., Claude, J. \& Strimmer, K. APE: analyses of phylogenetics and evolution in R language. Bioinformatics 20, 289-290 (2004).

65. Oksanen, J. et al. Vegan: community ecology package. https://CRAN.Rproject.org/package=vegan (2016).

66. Kembel, S. W. et al. Picante: R tools for integrating phylogenies and ecology. Bioinformatics 26, 1463-1464 (2010).

67. Wickham, H. \& Francois, R. dplyr: a grammar of data manipulation. R package version 0.4.3. https://CRAN.R-project.org/package=dplyr (2015).

68. Rosseel, Y. lavaan: an R package for structural equation modeling. J. Stat. Softw. 48 (2), 1-36 (2012). 
69. Oberski, D. lavaan.survey: an R package for complex survey analysis of structural equation models. J. Stat. Softw. 57 (1), 1-27 (2014).

70. Quinn, G. P. \& Keough, M. J. Experimental Design and Data Analysis for Biologists (Cambridge Univ. Press, 2005).

71. Grace, J. B., Anderson, T. M., Olff, H. \& Scheiner, S. M. On the specification of structural equation models for ecological systems. Ecol. Monogr. 80, 67-87 (2010).

72. Preacher, K. J. \& Hayes, A. F. Asymptotic and resampling strategies for assessing and comparing indirect effects in multiple mediator models. Behav. Res. Methods 40, 879891 (2008).

73. Rao, J. N. \& Wu, C. F. J. Resampling inference with complex survey data. J. Am. Stat. Assoc. 83, 231-241 (1988).

74. Bollen, K. A. Total, direct, and indirect effects in structural equation models. Soc. Method. 17, 37-69 (1987).

75. Hill, M. O. \& Gauch, H. G. J. Detrended correspondence analysis: an improved ordination technique. Vegetatio 42, 47-58 (1980).

76. Lepš, J. \& Šmilauer, P. Multivariate Analysis of Ecological Data using CANOCO (Cambridge Univ. Press, 2003).

\section{Extended Data Figure 1. Response of forest structure and tree nutrient concentrations to} $150 \mathrm{~m}$ of increasing elevation, terminating at treeline. Smoothing curves graphically illustrate trends for each of the seven regions; symbols represent individual plots $(n=101), P$ values $(F$ statistics in brackets) represent overall effects of elevation from treeline, NS, non-significant. a, Regionally significant decline in tree canopy height and (b) tree basal area. c, Regionally significant increases of stem density, particularly for southern hemisphere forests dominated by members of the Nothofagaceae. d, Regionally significant increases in basal area weighted tree foliar N (mass basis). e, Regionally non-significant responses of basal area weighted tree foliar $\mathrm{P}$ (mass basis). f, Regionally non-significant responses of basal area weighted tree foliar N/P. $R_{\mathrm{m}}^{2}$ is defined as being conditional on only the fixed effects, and $R_{\mathrm{c}}^{2}$ is defined as conditional on both the random effects of transect nested within region and the fixed effects. Test statistics from 
linear mixed effect models for stand characteristics and nutrient concentrations of all regions are given in Supplementary Tables 3 and 4.

Extended Data Figure 2. Representative photographs of treelines along elevational gradient transects in each of the seven regions sampled in this study. Details of each region are given in Supplementary Table 1.

Extended Data Figure 3. Coefficient of variation (s.d./mean $\times 100$ across regions) of coverweighted ground-layer plant foliar $\mathrm{N} / \mathrm{P}$ and total $\operatorname{root} \mathrm{N} / \mathrm{P}$ in relation to elevational groups relative to treeline position. Blue markers are means ( \pm 1 s.e.m.), grey bars are $95 \%$ confidence intervals. a, Significant decline of ground-layer plant N/P is evidence of stoichiometric convergence of community foliar N/P across regions in the colder alpine environments (slope of solid regression line $=-4.15 ; R^{2}=0.79, P=0.0176, F=15.18 ; R^{2}=0.92$ for dotted regression line in alpine). b, Root N/P, in contrast, was greatest just above the treeline and did not significantly decline with increasing elevation except in alpine $\left(R^{2}=0.95\right.$ for dotted regression line in alpine).

Extended Data Figure 4. The coupled relationship between $[\mathrm{N}]$ and $[\mathrm{P}]$ pools (mass basis) in foliage of community-weighted ground-layer plants and surface roots across all regions. a, Foliar versus root N. b, Foliar versus root P. Statistical $P$ values ( $F$ values) are given for mixed-effect linear regressions where foliar $\mathrm{N}$ and $\mathrm{P}$ is predicted by root $\mathrm{N}$ or $\mathrm{P}$. Most informative models also included region, vegetative community (forest versus alpine), and the random effect of transect. Inclusion of vegetative community substantially increased model fits (that is, Akaike information criteria values decreased by $\geq 19$ ), highlighting the large influence of tree roots on the resulting relationships. Comparable relationships with elevation from treeline provided for reference.

\section{Extended Data Figure 5. Abundance-weighted NRI values of understorey plant} communities across elevations, grouped by region. NRI does not increase systematically with elevation $(F=1.64, P=0.25$; best-fit linear mixed-effect model with region specified as a random effect), as would be expected if plant communities were phylogenetically clustered at higher elevations.

Extended Data Figure 6. Relationship between dominance (the inverse of evenness) and elevation. Dominance does not systematically vary with elevation $(F=1.18, P=0.29$; best-fit 
linear mixed-effect model with region specified as a random effect), as would be expected if plant communities became composed of more dominant species at higher elevations. $n=6$ mean values for each elevational level apart from Australia $(n=5)$.

\section{Extended Data Figure 7. Non-metric multidimensional scaling analysis of phylogenetic} community structure of all ground-layer plants across sites. Stress $=0.15$. Sites are displayed and dashed ellipses depict standard errors of all points grouped by region. PERMANOVA results of the Bray-Curtis dissimilarities for taxonomic (data not shown) and phylogenetic community composition yielded a significant difference between vegetative categories (alpine versus forest) (pseudo- $F=1.44, P=0.001$ and pseudo- $F=1.32, P=0.003$, respectively). However, multivariate dispersion of above versus below treeline communities did not differ significantly for taxonomic $(F=0.074, P=0.79)$ or phylogenetic $(F=1.35, P=0.25)$ composition overall, and comparisons of above versus below treeline communities within each region were found to be non-significant apart from differences in phylogenetic dispersion in Colorado and Patagonia, where communities showed greater divergence above treeline than below $(P<0.01) . n=6$ mean values for each elevational level apart from Australia $(n=5)$.

\section{Extended Data Figure 8. Regional responses of selected microbial and soil properties to} elevational gradients. The seven regions are arranged from low to high concentrations of total PLFAs. Smoothing curves graphically illustrate covariance of soil properties within each of the seven regions. a, Total microbial PLFA. b, Bacterial PLFA. c, Fungal PLFA. d, Actinomycete PLFA. e, Microbial SIR. f, Soil pH. g, SOM. Significant fixed effects of elevation from treeline $(E)$, vegetative community ( $V$, forest or alpine), or their interactions based on a linear mixedeffect models are given. $\bullet P \leq 0.10,{ }^{*} P<0.050,{ }^{* *} P<0.001,{ }^{* * *} P<0.0001$.

\section{Extended Data Figure 9. RDA of PLFA biomarker-based microbial community} composition in relation to soil environmental properties across all regions. Black, biomarker identity; blue, soil properties. Fungi are represented by 18:2 $\omega 6,9$, actinomycetes are represented by10Me17:0 and 10Me18:0, and all remaining PLFAs represent bacteria. a, Resulting RDA axes (soil $\mathrm{pH}$ dropped in stepwise model reduction) explains $85.9 \%$ (axis 1) and 93.4\% (axes 1+2), respectively, of the total variation in all species-environment relationships. b. When SOM is incorporated as a covariate to evaluate how remaining variance in PLFA biomarkers responds to the remaining statistically significant soil variables, $64.0 \%$ (axis 1) and $87.2 \%$ (axes $1+2$ ) of the 
total variation is explained in all species-environment relationships. TotP, total soil $\mathrm{P}$ on a volumetric basis; $\mathrm{N} / \mathrm{P}_{\min }$, soil mineral $\mathrm{N}$ to Bray-extractable $\mathrm{P}$ ratios; $\mathrm{C} / \mathrm{N}$, total soil carbon to nitrogen ratios. 